\title{
Aguafiestas porteñas. \\ Sexo y dinero en la micropolítica emocional abolicionista*
}

\author{
Deborah Daich**
}

\section{Resumen}

Este artículo se ocupa de las formas en que el dinero, el sexo y las emociones aparecen en la constitución de una determinada práctica política abolicionista de corte feminista. Se trata de intervenciones dirigidas tanto a combatir la trata y la prostitución como a desacreditar a las organizaciones de trabajadoras sexuales. Así, interesa atender a las formas en que la presencia misma de las trabajadoras sexuales en la arena pública, en tanto movimiento que reivindica derechos laborales, se ha tornado, para un sector del movimiento abolicionista argentino, en un obstáculo para su promesa de felicidad.

Palabras clave: Feminismo, Abolicionismo, Trabajo Sexual.

* Recibido en 23 de julio de 2016, aceptado en 22 de mayo de 2017.

** Investigadora Adjunta CONICET, Docente del Departamento de Ciencias Antropológicas, FILO,UBA. Integrante de la Colectiva de Antropólogas Feministas, IIEGE,FILO,UBA, Buenos Aires, Argentina. deborahdaich@gmail.com 
Killjoys from Buenos Aires.

Sex and Money in The Abolitionist Emotional Micropolitics

\begin{abstract}
This paper focus on the ways in which money, sex and emotions take part in the constitution of a certain abolitionist and feminist political practice. This practice intends both to combat trafficking and prostitution and to discredit sex workers organizations. Thus, I am interested in the ways in which the very presence of sex workers in the public arena, as a movement that claims for labor rights, has become, for a sector of the argentinian abolitionist movement, in an obstacle to its promise of happiness.
\end{abstract}

Keywords: Feminism, Abolitionism, Sex Work. 


\section{Introducción}

En una serie de sugerentes trabajos, Sara Ahmed (2004, $2008,2010)$ ha abordado el lugar de las emociones en la arena pública y su papel en la construcción de identidades colectivas; lo emocional de la política y la política emocional. Así, ha dado cuenta de las formas político-afectivas en las que se construyen "otros", por ejemplo, a través de la figura del inmigrante y del extranjero en una Europa temerosa de la migración y el terrorismo global, o a través de la figura de la feminista aguafiestas. Figuras que provocan emociones negativas y que intervienen, de este modo, tanto en la construcción de identidades diferenciadas como de diferencias $y$ desigualdades sociales que se traducen en prácticas concretas.

La figura de la feminista aguafiestas (feminist killjoy) es por demás interesante. La imagen que propone es la de aquella feminista que arruina el clima festivo al señalar, por ejemplo, que la alegría y las risas del momento provienen de chistes misóginos y sexistas. Es la que interrumpe el jolgorio, subrayando las relaciones de poder en un mundo desigual. La negatividad de su figura, sugiere Sara Ahmed, puede entenderse a la luz de la historia de la felicidad pública. Al desafiar ciertas ideas y estereotipos acerca del género, el feminismo ha ofrecido desafíos a cómo la felicidad es definida y por quiénes. Así pues, las feministas, al declararse como tales, son leídas como las destructoras de algo que es pensando por otros no sólo como bueno sino como la causa misma de la felicidad.

Las feministas, sostiene Ahmed, pueden ser aguafiestas precisamente porque se niegan a compartir ciertas cosas como necesariamente buenas o, mejor aún, porque no encuentran los objetos que prometen felicidad tan prometedores. El potencial transformador de la figura consiste en su capacidad de imaginar y proponer otros horizontes de felicidad, otros mundos posibles, a través de la impugnación de los actuales relatos públicos de felicidad. 
Dado que no existe un feminismo sino múltiples feminismos que convergen en un movimiento dinámico, sucede que algunas feministas, como las representadas en la figura de la "mujer negra enojada" (angry black woman), han estropeado la alegría feminista blanca y burguesa al señalar formas de racismo en el corazón mismo de las políticas feministas (Ahmed, 2008). Del mismo modo puede pensarse la irrupción de las lesbianas dentro del movimiento y, por qué no, de las trabajadoras sexuales. Todas han venido a plantear ciertas incomodidades, a aguar la fiesta desestabilizando los relatos hegemónicos sobre la equidad y el bienestar (o las promesas de felicidad) y proponiendo nuevos marcos de justicia social.

Así pues, en este trabajo me interesa atender a las formas en que la presencia misma de las trabajadoras sexuales en la arena pública, en tanto movimiento que reivindica derechos laborales, se ha tornado, para un sector del movimiento abolicionista local, en un obstáculo para su promesa de felicidad. Me interesa, en particular, prestar atención a las formas en que este abolicionismo feminista utiliza determinados discursos acerca del sexo y del dinero como insumos de su micropolítica emocional.

En los últimos tiempos, se han sucedido una serie de pequeños acontecimientos políticos producidos por este sector del movimiento abolicionista local que me han interpelado no sólo como antropóloga sino también como feminista y que me parece merecen atención. Se trata de intervenciones que este movimiento lleva adelante en el espacio público en fechas conmemorativas o de lucha, ${ }^{1}$ así como de intervenciones concretas con el fin de desacreditar e impugnar las actividades de reconocimiento de derechos que lleva adelante el movimiento de trabajadoras sexuales. En este último caso, por ejemplo, vale señalar las cartas dirigidas a los legisladores, o los escraches en sus despachos,

\footnotetext{
${ }^{1}$ Como el 8 de marzo, día internacional de la mujer; el 23 de septiembre, día internacional contra la explotación sexual y la trata de personas; el 25 de noviembre, día internacional de eliminación de la violencia contra las mujeres, entre otros.
} 
cuando aquellos presentan iniciativas apoyando a las trabajadoras sexuales o simplemente participan de algún encuentro organizado por la Asociación de Mujeres Meretrices de la Argentina. O también, por ejemplo, la campaña contra Amnistía Internacional cuando recientemente hizo pública su intención de discutir una política de descriminalización que favorezca los derechos humanos de quienes ejercen el trabajo sexual. ${ }^{2}$ Todas estas intervenciones han compartido una producción discursiva caracterizada por una fuerte carga emocional que moviliza e interpela a partir de imágenes de sufrimiento, en las que el sexo y el dinero ocupan un lugar muy particular.

De aquí que me interese en las formas en que, el dinero, el sexo y las emociones aparecen en la constitución de una determinada práctica política abolicionista de corte feminista. Parto de la idea de que la afectividad, en tanto experiencia emocional, es una dimensión importante de la política y un factor estructurante de los movimientos sociales. Pensando siempre, por supuesto, a las emociones como constructos sociales y culturales, como significados motivados culturalmente o socialmente articulados (Lutz; White, 1986; Leavitt, 1996). Ahora bien, antes de abordar específicamente esta micropolítica emocional, es preciso describir brevemente el contexto local $y$ quiénes son las abolicionistas a las que me refiero.

Este trabajo se basa en el trabajo de campo etnográfico que vengo llevando adelante desde el año 2011. ${ }^{3}$ Desde entonces, he

2 Durante el año 2015 Amnistía Internacional hizo pública su posición a favor de la despenalización como forma de evitar las vulneraciones cotidianas a los derechos humanos de los y las trabajadoras sexuales. Ello provocó una serie de reacciones, entre ellas, cartas y solicitadas impulsadas por la Coalición contra el Tráfico de Mujeres y pronunciamientos públicos de actrices de Hollywood. En la arena local, se replicaron las protestas y críticas, motorizadas principalmente por la Campaña Abolicionista. Sobre la posición de Amnistía y su investigación puede consultarse: http://www.amnistia.org.ar/noticias-y-documentos/archivo-denoticias/amnist\%C3\%ADa-internacional-publica-su-pol\%C3\%ADtica-y-suinvestigac

${ }^{3}$ Se trata de una investigación empírica llevada adelante en el marco de mi proyecto actual como Investigadora CONICET y forma parte, también, de los 
estado trabajando sobre el control de la prostitución o, mejor dicho, sobre la experiencia de las trabajadoras sexuales acerca del control jurídico -policial y la violencia institucional. He estado reflexionando, además, sobre las relaciones entre estas mujeres y los agentes de su control, así como también sobre los discursos públicos respecto del sexo comercial, los que parecen estar alimentando cierto "pánico sexual" y tornándose insumos para políticas de control.

\section{Del abolicionismo feminista porteño}

El modelo abolicionista actual, que suele apoyar su retórica en el Convenio de Naciones Unidas de Represión de la Trata de Personas y Explotación de la Prostitución Ajena de 1949 y otros tratados, subraya la incompatibilidad de la prostitución con la dignidad humana, considera necesaria la persecución y criminalización de la explotación sexual ajena, y califica a quienes ejercen la prostitución como víctimas ${ }^{4}$. Este abolicionismo

proyectos PIP Género y violencia en el mercado del sexo: policía y prostitución (CONICET) y del proyecto UBACYT El gobierno de la prostitución en la Ciudad de Buenos Aires: Actores, lógicas profesionales y gestión de los ilegalismos (UBA).

4 Generalmente en el debate internacional respecto de la prostitución se reconocen tres modelos referidos a su regulación: abolicionismo (implica la persecución de la explotación sexual ajena y quienes ejercen la prostitución son vistas generalmente como víctimas), prohibicionismo (implica la prohibición y persecución de toda forma de explotación sexual y prohibición también del ejercicio de la prostitución, y quienes ofrecen servicios sexuales propios o ajenos son vistos como delincuentes) y reglamentarismo (regulación a través del establecimiento de controles sanitarios, espaciales y administrativos. Este modelo ha considerado la prostitución como un "mal necesario" y a quienes la ejercen como desviados y potenciales conductores del peligro venéreo). Es preciso sumar un cuarto modelo, generalmente invisibilizado, que es el de legalización. Este último es el propuesto por las organizaciones de trabajadoras sexuales para plantear el reconocimiento de la oferta de servicios sexuales como una actividad económica legítima, y para acabar con la clandestinización, la violencia y la marginalidad. A diferencia del reglamentarismo, el modelo de legalización pondera la ampliación de los derechos humanos de las personas que ofrecen sexo comercial, defendiendo las libertades individuales y el derecho al trabajo 
considera, además, que la prostitución debe ser leída fundamentalmente como violencia contra las mujeres y las personas trans.

No pretendo detenerme aquí en el lugar que la prostitución ha ocupado dentro de las discusiones del feminismo local de las últimas décadas ni en desarrollos exhaustivos respecto de las trayectorias políticas de las organizaciones, simplemente intento situar algunas cuestiones que puedan contextualizar la práctica política en cuestión.

Así, cabe resaltar que a la vuelta de la democracia, en 1983, la prostitución no ocupaba verdaderamente un espacio central en las discusiones y acciones del movimiento feminista argentino. Recién en los años noventa, y con más fuerza, entrado el siglo XXI, se tornaría una cuestión a ser problematizada. En los años noventa, cuando la Ciudad de Buenos Aires ganó su autonomía, los edictos policiales -entre ellos, los que perseguían la prostitución y el travestismo- fueron derogados, dando lugar a la discusión de un nuevo ordenamiento contravencional: el Código de Convivencia Urbano. En ese entonces, feministas, travestis $y$ trabajadoras sexuales coincidieron tanto en el reclamo por el fin de los edictos, como en la denuncia contra la redacción de artículos que, en el nuevo Código, penalizaran la oferta sexual en las calles. En esa época, algunas feministas formaron la Asamblea Raquel Liberman ${ }^{5}$, grupo que se oponía a esta represión policial

(Rubio 2008, Mestre i Mestre, 2008). Argentina tiene, desde el año 1936, una posición abolicionista que sin embargo no implica la no persecución de las personas que ofrecen sexo comercial puesto que subsisten una serie de normas de mayor o menor jerarquía que o bien la penan en forma directa, o bien su aplicación, en la práctica, implica la criminalización de aquellas personas. Asimismo, la campaña anti-trata de los últimos años se dirige al mercado sexual todo, por lo que sus políticas afectan a quienes ejercen el trabajo sexual de forma autónoma. Para estos temas ver, por ejemplo, Daich (2012), Daich y Varela (2014).

5 Raquel Liberman se tornó un personaje reconocido cuando, en 1930, acusó a la Zwi Migdal de explotarla sexualmente. A partir de su denuncia -y en una coyuntura política particular- se desató no sólo una serie de arrestos sino también un escándalo público y político así como una serie de debates legislativos. Estos 
contra las trabajadoras sexuales y al mismo tiempo pretendía visibilizar el proxenetismo y señalar a la prostitución como una institución patriarcal. Muchas de estas militantes feministas confluirían, años más tarde, en la Campaña Abolicionista.

En este período se formaba, también, la primera asociación de prostitutas: AMAR -Asociación de Meretrices Argentinas. Esta agrupación nació en el año 1995, a partir del encuentro de mujeres que ejercían la prostitución principalmente en los barrios porteños de Flores y Constitución. Estas mujeres participaban de unos talleres de autocuidado organizados por dos antropólogas y, a partir de estos encuentros, comenzaron luego a discutir sus problemas en las calles, en particular, en relación con la policía. Así, mujeres y travestis que participaban del mercado sexual callejero comenzaron a reunirse y organizarse frente a la violencia policial. Sus primeras reuniones tuvieron lugar en un espacio prestado por la Asociación de Trabajadores del Estado (ATE) y luego terminaron incorporándose a la Central de Trabajadores Argentinos (CTA $)^{6}$ en tanto Asociación de Mujeres Meretrices de la Argentina (AMMAR). A partir de entonces, la organización comenzó a trabajar con distintos proyectos de prevención de enfermedades de transmisión sexual, financiados primero por el Ministerio de Salud de la Nación (Programa LUSIDA 1998). En el año 1997, AMMAR se incorporó a la RedTRASEX (red de trabajadoras sexuales de Latinoamérica y el Caribe) y continuó profundizando su trabajo colectivo de construcción política. Así,

últimos terminarían clausurando la época reglamentarista de la Argentina. Zwi Migdal fue una organización de tratantes y traficantes de personas, y rufianes judíos que operaba burdeles legales y clandestinos en todo el territorio nacional (Guy, 1994).

${ }^{6}$ La CTA surge formalmente en el año 1992 pero su historia se remonta al año 1989 cuando un conjunto de sindicatos se separa de la estructura mayoritaria de la Confederación General de Trabajadores (CGT). La CTA ha buscado, desde sus orígenes, integrar experiencias asociativas que exceden la categoría tradicional de representación gremial. Así, incorporó organizaciones de pueblos originarios, organizaciones campesinas, barriales, de desocupados, etc. Ello así porque la CTA propone una utilización inclusiva del término clase trabajadora, no restringida a la posición en el mercado de trabajo (Ferrero y Gurrera, 2007). 
fue realizando distintas presentaciones y proyectos ${ }^{7}$ y actualmente pugna por una ley que reconozca los derechos laborales de quienes ejercen el trabajo sexual.

En el año 2002, en una Asamblea Nacional de AMMAR y frente a la posibilidad de sindicalizar la organización, ésta se dividió en posturas opuestas. Quedaron entonces conformadas dos agrupaciones; por un lado, AMMAR CTA como sindicato de trabajadoras sexuales $y$, por el otro, AMMAR Capital (hoy AMMADH), agrupación de mujeres en situación de prostitución. Esta última organización adquirió una postura abolicionista, se organizó primero en una sede en el barrio de Flores y luego se instaló en una oficina cedida por el Organismo Nacional de Bienes del Estado (ONABE) en el barrio de Once. Las integrantes de AMMADH bregan por políticas públicas de inclusión de personas en situación de prostitución, articulan con organismos del estado para brindar en su espacio talleres de oficios (costura, electricidad) así como facilidades para finalizar la escuela, entre otras actividades.

Ahora bien, la cuestión de la prostitución y la trata comenzó a ocupar un espacio más prominente en la arena pública comenzado el siglo XXI. En el año 2004, nuevas reformas al Código Contravencional fueron presentadas en la Legislatura porteña. Propuestas para penalizar la protesta social, bajar la edad de imputabilidad, reprimir la venta ambulante y prohibir la prostitución callejera generaron una nueva polémica y la movilización de organizaciones de la sociedad civil. ${ }^{8}$ En esa época de discusión sobre el control de la prostitución (y otras contravenciones), las prostitutas tuvieron una visibilización social importante, pero no sólo las organizaciones sino también las

7 Por ejemplo, el proyecto PROFAM (CNM, BID, 2005) para trabajar sobre violencia contra las mujeres, el financiamiento de MAMACASH para trabajar sobre promoción de derechos, o el financiamiento del Fondo Mundial de lucha contra el Sida, la Tuberculosis y la Malaria ("Actividades de Apoyo para la Prevención y Control del VIH/Sida en Argentina"-AMMAR-CTA 2006 y 2011), entre tantos otros.

${ }^{8}$ Para este tema ver Tiscornia et. al. 2004, Sabsay 2011. 
prostitutas como personajes sociales. Entre ellas, una serie de mujeres dominicanas que ejercían la prostitución en las calles de Buenos Aires y que adquirieron visibilidad por la publicación en los medios de comunicación de historias que comprometían a algunas de ellas en tramas de trata y tráfico de mujeres. ${ }^{9}$ Ese año, también, se inició la red virtual "red no a la trata" que denunciaba el secuestro de mujeres para las redes de prostitución y casos que luego serían emblemáticos, como el de Marita Verón. ${ }^{10}$ Poco a poco la campaña anti-trata comenzó a tomar forma en la Argentina y, con ella, la prostitución ocupó el centro de la escena. Surgieron entonces una serie de organizaciones anti-trata, algunas vinculadas a las militancias feministas locales, algunas con financiamiento internacional. Cecilia Varela (2015) ha explicado exhaustivamente esa "migración" de la campaña anti-trata de los espacios transnacionales hacia nuestro país, dando cuenta de los actores claves en esa acción, como por ejemplo el Departamento de Estado norteamericano -que, a través de sus Tip Reports, demandó cambios en la legislación argentina. Así, en el año 2008 se sancionó una primera ley de trata que luego, en el año 2012 y después del fallo absolutorio en el caso Verón, fuera reformada siguiendo las modificaciones de corte abolicionista pretendidas por las organizaciones anti-trata. Desde entonces, la ley no distingue entre prostitución forzada y prostitución voluntaria.

El abanico de organizaciones abolicionistas y anti-trata se ha multiplicado durante estos últimos años y no es mi intención hacer aquí un mapeo de todas ellas. ${ }^{11}$ Sí interesa, para este trabajo, recuperar a la Campaña Abolicionista "Ni una mujer más víctima de las redes de prostitución" ${ }^{12}$ conformada en el año 2007 por

9 Ver, por ejemplo, el informe de OIM de 2003 "Migración, prostitución y trata de mujeres dominicanas en la Argentina".

${ }^{10}$ Se trata del caso del secuestro y desaparición de María de los Ángeles Verón, ocurrido en el año 2002 en la provincia de Tucumán.

${ }^{11}$ Ver, por ejemplo, Varela 2012.

${ }^{12}$ Puede consultarse su página web:

http://campaniaabolicionista.blogspot.com.ar/ 
distintas organizaciones feministas, algunas de ellas de larga trayectoria como ATEM. ${ }^{13}$ Esta Campaña organiza anualmente jornadas abolicionistas de discusión y una serie de acciones públicas en los días conmemorativos o de lucha. Junto con otras organizaciones conforman el Frente Abolicionista Nacional (FAN). Son muchas las agrupaciones de este espectro abolicionista, entre ellas AMADH, la organización de mujeres en situación de prostitución, y ALLIT, Asociación de lucha por la Identidad Travesti ${ }^{14}$, de las cuales no me voy a ocupar específicamente. Así, no voy a enfocarme en militantes abolicionistas que hayan participado del mercado sexual, ya sean víctimas de trata o mujeres en situación de prostitución. Antes bien, la mirada está puesta sobre militantes feministas que están o bien nucleadas en esta Campaña Abolicionista o en el FAN, o bien participan de agrupaciones que confluyen en actividades compartidas con la Campaña. Se trata de militantes abolicionistas que se reconocen como parte de organizaciones feministas, lesbo-feministas, lésbicas y queer. También puede tratarse de militantes abolicionistas que se reconocen dentro de algunas de estas tradiciones pero no pertenecen formalmente a ninguna organización (aunque sí participan de las actividades de la Campaña).

\footnotetext{
${ }^{13}$ La Asociación de Trabajo y Estudio de la Mujer, 25 de noviembre (ATEM), creada en 1982, es una organización feminista autónoma de larga trayectoria en la Argentina.

${ }^{14}$ La politización que de la prostitución han realizado algunas organizaciones de travestis merece una atención aparte por lo que no he de ocuparme de ellas en este trabajo. Al respecto, es interesante la tesis doctoral de Soledad Cutuli (2015) donde, a propósito de ALLIT, señala la construcción de un relato que liga travestismo con exclusión y prostitución, en tanto narrativa clave en la politización travesti y en su reclamo por un trabajo digno. En este punto, señala al abolicionismo como un relato que travestis activistas y mujeres feministas utilizaron para la construcción de aquella narrativa y que contribuyó a la politización travesti. En este sentido, afirma que el abolicionismo no es un punto de partida. Antes bien, se trata de un punto de llegada que le permitió a esta organización particular construir el relato de la prostitución como destino inevitable y demandar entonces la inclusión a través del trabajo digno.
} 
La Campaña Abolicionista sostiene que la trata con fines de explotación sexual y la prostitución son fenómenos inseparables, que la prostitución es una institución patriarcal basada en la desigualdad entre varones y mujeres y que no puede, bajo ningún concepto, ser considerada trabajo. Las integrantes de la Campaña afirman que la prostitución es una forma de violencia de género en la que la identidad y la subjetividad de las mujeres se ven comprometidas produciendo daños físicos y psíquicos; que es una institución fundamental en la construcción de una sexualidad basada en el dominio masculino y la sumisión femenina y en la cosificación de los cuerpos; que nunca es una elección libre (independientemente incluso de los contextos en los que tenga lugar y de la clase social a la que se pertenezca) y, por tanto, no puede pensarse nunca en un libre consentimiento.

Quizás pueda afirmarse, esquemáticamente, que hasta el año 2002, y a pesar de sus posibles diferencias, feministas y prostitutas compartían un frente de lucha común. Han compartido una historia conjunta de lucha en contra de los edictos policiales y en contra de la redacción de artículos represivos en los códigos contravencionales. Pero desde que un grupo de prostitutas adoptó para sí la identidad de trabajadoras sexuales, la alianza se vio resquebrajada. De un lado quedaron feministas abolicionistas y mujeres en situación de prostitución $y$, del otro, trabajadoras sexuales $^{15}$. Desde entonces, buena parte del discurso abolicionista local no sólo remarcó el carácter de víctima de quienes se han visto envueltas en el mercado del sexo sino que, además, denostó y desprestigió, en cada posible oportunidad, a quienes enarbolaron la bandera del trabajo sexual.

Así pues, quisiera detenerme ahora en las formas en que estos discursos abolicionistas han participado de la construcción de cierto ideario acerca del sexo pago como violencia de género así

\footnotetext{
${ }^{15}$ Recién en el año 2016 se conformó una agrupación que apoya la reivindicación de los derechos de las y los trabajadores sexuales. Allí confluyen personas de distintas trayectorias profesionales y militantes, entre ellas varias feministas. Se trata del FUERTSA, Frente de Unidad Emancipatorio por el Reconocimiento de los Derechos de Trabajadorxs Sexuales en Argentina.
} 
como también en las formas en que han utilizado el dinero como argumento para desacreditar a las organizaciones de trabajadoras sexuales y sus aliados.

\section{De la prostitución a la "violación paga"}

Las formas contemporáneas del abolicionismo consideran que la prostitución es una expresión extrema de la dominación patriarcal, que se trata de una forma de violencia contra las mujeres y, por tanto, una violación a los derechos de las mujeres. Así, independientemente de la diversidad de experiencias y de trayectorias posibles, el sexo comercial es, en este discurso abolicionista, siempre violencia. Es, según una integrante de ATEM y de la Campaña Abolicionista, una "afrenta a la dignidad humana".

Los discursos que las militantes abolicionistas ponen en circulación construyen imágenes de una Sexualidad libre y placentera vs. una Sexualidad violentada por las relaciones de poder que hacen al dominio masculino y erosionada por el dinero. Así, algunas de las consignas que pueden leerse en las intervenciones públicas ${ }^{16}$ que lleva adelante el movimiento abolicionista refieren

\footnotetext{
${ }^{16}$ Estas intervenciones tienen lugar en el espacio público, cuando las militantes participan de eventos organizados o se manifiestan en las calles; consignas que pueden estar presentes en sus exposiciones o bien pueden ser cánticos coreados en marchas, o slogans para difundir a través de volantes. Las intervenciones también tienen lugar en las redes sociales, a través de listas de correo electrónico como RIMA, de foros de discusión en Facebook y similares. Respecto de este último recurso, cable aclarar que, como bien sugiere Adriana Piscitelli, el llamado espacio virtual es una de las esferas constituyentes de las sociedades complejas por lo que, aun cuando la idea de una etnografía de esos lugares virtuales sea objeto de debate y discusión, es innegable que una lectura antropológica de esos espacios tiene sentido (2005:288). Aunque todavía se debatan cuestiones éticas y metodológicas, entre otras, las investigaciones en y del ciberespacio y de la cibercultura vienen teniendo legitimidad en el ámbito antropológico. Si consideramos que lo virtual no se opone a lo real sino que constituye una esfera singular de la realidad (Guimarães, 2000), como tal concierne claramente a la
} 
La obediencia sexual no es facturable, es violencia de género. ${ }^{17}$

Sin deseo sexual, es abuso y desigualdad.

Si hay necesidad, no hay consentimiento.

Nunca una sexualidad libre puede tener como fin ser objeto de otro.

La prostitución es violencia de género hacia mujeres y travestis niñas y adultas. La trata y prostitución son dos caras de la misma violencia.

Reglamentar la institución de la prostitución como "trabajo" es legitimar la violencia machista.

Los varones que "pagan por sexo" son los principales responsables. No son "clientes" son prostituyentes.

Basta de persecución a las personas en situación de prostitución. Restitución inmediata de derechos sociales, económicos y culturales.

Por una sexualidad libre y placentera para todas.

Las militantes abolicionistas señalan la desigualdad de clase presente en el mercado del sexo y resaltan el hecho de que muchas mujeres ofrecen sexo comercial "por necesidad" denunciando, junto con ello, que el cuerpo de las mujeres no debería ser una mercancía puesta en el mercado. Por ejemplo, refería una integrante de la Campaña Abolicionista en una reciente entrevista en un diario local:

antropología - cuyo métier ha sido ocuparse de la historia de la vida como ha sido vivida y como es vivida en este preciso momento (Escobar, 2005).

${ }^{17}$ Vale señalar que esta consigna en particular fue parte de una reacción a la campaña de visibilización del trabajo sexual "el trabajo sexual es trabajo" impulsada por AMMAR durante el año 2015. La campaña proponía imaginar cómo facturarían sus servicios las trabajadoras sexuales, si su menester fuese legal. Ver: http://www.ammar.org.ar/CAMPANA-EL-TRABAJO-SEXUAL-ESUN.html 
que la sexualidad no esté coaccionada por el dinero. Porque el dinero determina el momento en que van a tener que dejarse eyacular sobre su cuerpo. Porque a un tipo se le ocurre porque tiene plata, no porque es su deseo. ${ }^{18}$

Pero estas militantes insisten, también, en que la pobreza es sólo un agravante puesto que, en verdad, las causas de la prostitución hay que buscarlas en las relaciones de género. Como señalaba una integrante de la Campaña Abolicionista:

(...) porque la base de la prostitución no es la pobreza, la pobreza es un agravante... son las relaciones de género. Hay una característica que es la violencia de género. En todos los casos, la base es la relación jerárquica entre varones y mujeres, esto es común a todos los casos, a la prostitución de Constitución y a la prostitución de alto nivel. (Entrevista a una integrante de la Campaña Abolicionista)

Como desde una perspectiva feminista abolicionista lo que resulta fundacional de la subordinación femenina es la explotación sexual entendida como una condición política, antes que económica, poco importa, finalmente, para este discurso, las condiciones en que pueda llevarse adelante el trabajo sexual. El problema no es el cómo sino el qué. El sexo y la sexualidad de las mujeres aparecen aquí constreñidos por una lógica patriarcal que, dinero de por medio, habilita la cosificación del otro para el consumo personal, tornándose un acto degradante y/o deshumanizador.

Pero ¿cómo se transmite este mensaje? Esta militancia feminista abolicionista se expresa a través de narrativas que chocan y de un lenguaje sexual explícito y exagerado, capaces de despertar respuestas emocionales en la audiencia:

${ }^{18} \mathrm{http}: / /$ www.pagina12.com.ar/diario/dialogos/21-281077-2015-09-07.html 
no es lo mismo estar expuestas en nuestra labor cotidiana a que te metan la pija o las manos o un objeto por cualquier orificio del cuerpo sin que queramos (...)

la prostitución es que te puedan coger a cambio de dinero, que la carne sensible deba entregarse por plata con algo de ganas, muchas, pocas o sin ganas en absoluto...vale preguntarnos si el asco a limpiar un inodoro ajeno es el mismo asco que tenemos a que un borracho desagradable -que en general buscamos tener bien lejos- esté con su pija en nuestro cuerpo jadeándonos al oído. ("Si me tengo que prostituir no es mi revolución!" Fanzine de Grupo Malezaintegrantes del FAN)

hablemos de qué nos pasa a las mujeres cuando en vez de calentura, hay asco y miedo. Cuando toleramos los penes en nuestras vaginas, anos y bocas hasta la repulsión (...) hablemos del semen no deseado, de las palizas, de los escupitajos, los insultos, los manoseos, el sudor y la mierda de los clientes. Hablar de prostitución sin hablar de los penes-picana es tomarnos el pelo a nosotras mismas. (Ponencia de Andrea Benítez - de la Colectiva feminista abolicionista Pepita Guerra- en las 4 Jornadas Abolicionistas, 2014)

no hay forma de convertir a la prostitución en un trabajo seguro porque su misma práctica es ya un abuso (...) implica el desdoblamiento emocional, la disociación entre la mente y el cuerpo, para no sentir, para consentir relaciones sexuales sin deseo" ("Si me tengo que prostituir no es $\mathrm{mi}$ revolución! Fanzine de Grupo Maleza- integrantes del FAN)

Este tipo de discursos suele condensarse en las consignas que las militantes llevan en los carteles en cada intervención pública y que viralizan por las redes sociales, tales como "El hombre que va de putas no paga por sexo, paga por ejercer violencia en forma de sexo", "Prostitución es igual a violación paga" o "Los clientes son violadores con billetes". Así pues, los discursos abolicionistas movilizan imágenes sensoriales que 
evocan angustia, asco y rechazo. Como el trabajo sexual es retratado como una violación, resulta difícil no empatizar con semejante sufrimiento.

Por supuesto que no me estoy ocupando aquí del sufrimiento real que muchas personas involucradas en el mercado del sexo pueden efectivamente experimentar. No estoy discutiendo si existen historias de miseria, violencia y opresión alrededor de la prostitución. ${ }^{19}$ Mi interés es reflexionar sobre este discurso performativo abolicionista, sobre su narrativa acerca del sufrimiento encarnado por una prostitución que se asume a priori y siempre como violencia de género. Me interesa pensar el cómo de ese discurso que aparece cada vez más virulento, en particular, cuando se dirige a quienes se autoadscriben a la identidad de trabajadoras sexuales. Cómo, a través de esta práctica política, se ponen en circulación emociones que no sólo intervienen en la

${ }^{19}$ Como bien señala Piscitelli (2014) para Brasil, los estudios antropológicos sobre prostitución no se ocupaban específicamente de la violencia presente en la vida de las y los trabajadores sexuales, reticencia que podría explicarse por los esfuerzos en distanciarse de lecturas y autoras abolicionistas que consideran la prostitución como inherentemente violenta. Pero, de un tiempo a esta parte, sostiene la autora, los estudios sobre intercambios sexuales y económicos dan cuenta de las diversas dimensiones de la violencia que permean esas relaciones. Así por ejemplo, menciona los trabajos de José Miguel Nieto Olivar sobre la violencia de Estado y los de Soraya Simões sobre violencia policial. También los trabajos que muestran la violencia simbólica, como las prácticas de no reconocimiento de la prostitutas en ciertos sectores feministas, trabajadas por Sonia Correa y José Nieto Olivar. También las violencias que permean las relaciones entre trabajadoras sexuales y organizaciones de rescate, y las violencias de las disposiciones y legislaciones anti-trata que se convierten en control migratorio, entre tantas otras. Una serie de trabajos se han ocupado también, señala Piscitelli, de otras dimensiones de la violencia que tienen lugar en el ámbito de la intimidad, en relaciones con clientes, novios o esposos, y con gigolós, como los trabajos de Leticia Tedesco. Para la Argentina, cabe mencionar la compilación de Daich y Sirimarco (2015), los trabajos de Cecilia Varela y Deborah Daich (2014) sobre los efectos de las políticas anti-trata en términos de vulneración de derechos y violencias físicas, materiales y simbólicas sobre las trabajadoras del sexo, y los trabajos de Santiago Morcillo (2015) y Carolina Justo Von Lurzer (2006) que recuperan la dimensión de la violencia simbólica de la estigmatización, entre otros. 
construcción del propio grupo sino también en la delimitación de un otro (Ahmed, 2004), cómo esta circulación crea y re crea las condiciones para determinadas prácticas políticas y conlleva, asimismo, una serie de valoraciones morales.

Cabe subrayar que las emociones no sólo refieren al plano individual, si bien son subjetivamente sentidas e interpretadas, son seres humanos socializados quienes las sienten en contextos sociales específicos, ellas son social y simbólicamente producidas, expresadas y sentidas (Leavitt, 1996). Así pues, lo emocional, los sentimientos, hablan de fenómenos sociales que dan cuenta de situaciones, relaciones y posiciones morales (Lutz, 1986). La explicitación de las emociones no implica sólo una afirmación sobre el estado interno de los sujetos, sino también una afirmación sobre las relaciones que vinculan a los sujetos entre sí y a éstos con distintos eventos. Ello así, porque la emoción se finca sobre las relaciones sociales: "los sistemas de significado emocional reflejan esas relaciones y, a través de la constitución emocional del comportamiento social, las estructuran (Lutz, 1982; Lutz y White, 1986). La emoción sólo puede entonces manifestarse empotrada sobre lazos de sociabilidad, ya que es el conocimiento de estos lazos y de estas relaciones los que brindan la posibilidad misma de esa emoción" (Daich, Pita y Sirimarco, 2007:77). ${ }^{20}$

\footnotetext{
${ }^{20}$ Si bien las emociones habían sido abordadas de forma más o menos directa en distintos estudios antropológicos, es recién en los años ochenta del siglo XX cuando lo emocional se convierte en verdadero objeto de estudio. Desde entonces se han dado una serie de debates, como las oposiciones y/o distintas combinaciones entre los enfoques psico-biológico y constructivista, las tensiones entre los enfoques que asumen la universalidad de las emociones naturales o preculturales vs. los enfoques relativistas de emociones culturales, o las críticas que desde el rescate de la experiencia corporal sensorial se le han hecho al modelo constructivista por su excesivo énfasis en lo comunicacional y discursivo. Dentro de este extenso campo, ciertos autores distinguen entre emociones (símbolos socialmente articulados), sentimientos (sensaciones personales que no se encuentran culturalmente articuladas) y afectos (experiencia no consciente de una intensidad corporal), aunque la caracterización de las distintas categorías es aun objeto de debate y de variabilidad.
} 


\section{Del dinero y el "proxenetismo internacional"}

Como sostuve párrafos más arriba, en este trabajo me interesa prestar atención a un abolicionismo particular, que utiliza determinados discursos acerca del sexo y del dinero como insumos de su micropolítica emocional. Sexo y dinero aparecen no sólo imbricados en un discurso acerca de la prostitución como violencia de género sino también como argumento para desacreditar a las organizaciones de trabajadoras sexuales y sus potenciales aliados, como los representantes de ONU SIDA, compañeros y compañeras de la CTA, académicas y legisladores.

Si la prostitución siempre es violencia, claramente no podría ser nunca trabajo por lo que las organizaciones abolicionistas dirigen sus acciones a disputar los sentidos puestos en juego por las asociaciones de trabajadoras sexuales y proclamarse en contra de su pedido de reconocimiento de derechos laborales. Así, las agrupaciones abolicionistas han redactado cartas a los legisladores que acompañaron los proyectos de ley presentados por AMMAR, oponiéndose a dichos proyectos. Han realizado, también, escraches a estos políticos, irrumpiendo en sus despachos con sus carteles y voceando sus consignas. Vale como ejemplo lo que sucedió recientemente en la provincia de Neuquén, cuando en vistas a una actividad organizada por AMMAR, una de las invitadas, diputada del Frente Para la Victoria, recibió la siguiente carta de una integrante de la Campaña Abolicionista:

CABA 17/09/2015

Sra. Diputada

En razón de estar anunciado que Ud participaría en "Primera mesa de incidencia política: Hacia el reconocimiento del Trabajo Sexual" quisiera expresarle:

Está Ud. actuando como facilitadora de la prostitución con la complicidad de sindicalistas financiadas por el proxenetismo internacional. 


\begin{abstract}
(...)
Está incurriendo Ud. en sostenedora de la violencia de género ya que la prostitución se apoya en desigualdades entre varones y mujeres/travestis, en el ejercicio de poder sobre colectivos vulnerabilizados. No importando el consentimiento de la victimizada en este acto y sí las acciones planificadas, que Ud auspicia, para someter a las personas.
\end{abstract}

Invito a Ud. a releer la nota enviada recientemente oponiéndonos a la reglamentación/regulación desde el movimiento abolicionista.

Queda Ud. notificado

Atte.,

XXXX

Integrante de la Campaña Abolicionista "Ni una mujer más víctima de las redes de prostitución.

Estas militantes han realizado también campañas en las redes sociales donde han acusado a algunos legisladores de "putañeros" y a gremialistas de proxenetas o facilitadores. ${ }^{21} \mathrm{En}$

\footnotetext{
${ }^{21}$ Recientemente, militantes feministas abolicionistas pretendieron realizar un escrache al titular de la CTA, en el marco del Congreso Pedagógico organizado por Utelpa en la ciudad de Santa Rosa [http://kasandrxs.radioteca.net/derechoshumanos/no-a-la-prostitucion-y-trata-de-personas?page $=4]$. Ya en el año 2014, la Campaña Abolicionista presentaba sus jornadas denunciando a un "sistema prostituyente" integrado por "prostituyentes, proxenetas, fiolos, todos los que lucran, apoyan o lo sostienen, ya sea desde la sociedad o el estado: funcionarios de los 3 poderes, fuerzas de seguridad, taxistas, remiseros o mozos de bares que entregan tarjetas, dueños o regentes de hoteles, centrales sindicales que se constituyen en facilitadoras con posicionamientos reglamentaristas". También fue tildada de "proxeneta" la organización Amnistía Internacional cuando recientemente presentó su propuesta de despenalización del trabajo sexual como forma de garantizar los derechos de las personas que lo ejercen. Una integrante de la Campaña Abolicionista refería lo siguiente: "Amnistía Internacional dejo de defender los derechos humanos y, sobre todo, los derechos de las humanas, para defender a proxenetas y prostituyentes".
} 
esta operación de desacreditación y de impugnación de las trabajadoras sexuales organizadas, las abolicionistas invocan nuevamente al dinero como elemento corruptor.

Así, las militantes abolicionistas se hacen eco de ciertas interpretaciones clásicas sobre el dinero que lo sitúan como la causa de la impersonalización de las relaciones sociales, la amenaza al orden moral. Las relaciones monetarias se ven como la antítesis de las relaciones de parentesco y amistad, las que se asumen personales, permanentes, morales y altruistas. De aquí que desde estas teorizaciones se suela argumentar que la impersonalidad y el anonimato del dinero dan lugar a relaciones impersonales -propias del mercado- que se tornan destructivas de la comunidad. El problema parece ser que se asume que el dinero señala una esfera de relaciones económicas autónoma, separada, que sería inherentemente impersonal, transitoria, amoral y calculadora. Una esfera que sería incompatible con las relaciones altruistas, solidarias y comprometidas. Para los occidentales, la teoría nativa reza que "el dinero es malo".

De este modo, las militantes abolicionistas han aprovechado cada instancia de debate o presentación pública para señalar, en primer lugar, que no habría que mezclar sexo con dinero puesto que pertenecerían a esferas separadas: economía vs. intimidad. El argumento abolicionista señala a la intimidad como un espacio también reglado por relaciones de dominación al tiempo que subraya al dinero como un elemento más del poder patriarcal y de corrupción de los aspectos emocionales y morales de una intimidad ideal.

En segundo lugar, han insistido con un discurso que señala al dinero del financiamiento internacional, que las organizaciones de trabajadoras sexuales se han agenciado, como aquello que le resta autenticidad a ese movimiento 22 . "El dinero lo cambia todo"

\footnotetext{
${ }^{22}$ En algunos aspectos, esta cuestión de la presunta autonomía perdida como consecuencia del financiamiento evoca las discusiones del feminismo "autónomo" con el "institucional".
} 
reza el dicho popular, y para las militantes abolicionistas, el dinero de las organizaciones las cambió para mal.

Últimamente, ciertas militantes abolicionistas señalan que las organizaciones de trabajadoras sexuales poseen "demasiado" financiamiento ${ }^{23}$ dirigido, en verdad, a coptarlas; las he escuchado decir públicamente que sus dirigentes ya no ejercían el trabajo sexual o no lo habían ejercido nunca -por lo que vivían del gremio o del trabajo de sus compañeras, lo que las tornaba proxenetas y "fiolas sindicalistas". Recientemente las he escuchado decir, a viva voz, que la actual secretaria general de AMMAR no ejercía el trabajo sexual sino que vivía del trabajo de sus compañeras; del mismo modo hablaban respecto de la anterior Secretaria Nacional y de la que entonces era Secretaria de Ciudad de Buenos Aires:

Jorgelina ha trabajado en la calle, no trabaja más por la organización. Lo que les ha permitido a Jorgelina y a Elena no estar en la calle es porque tienen el financiamiento de su organización. Ellas no están en la calle porque otras están en la calle, las que representan (Entrevista a una integrante de la Campaña Abolicionista, año 2011).

Pero no sólo se han ocupado de desprestigiar a las dirigentes, también a aquellos grupos con los que se han aliado $e$ incluso han llegado a decir que había académicas pagas para instalar la falsa idea de que existe el "trabajo sexual" y el libre consentimiento. ${ }^{24}$ Crearon, asimismo, un personaje enigmático,

\footnotetext{
${ }^{23}$ En general, se refieren con ello al proyecto de 5 años de la RedTrasex en asociación con la OIM (y del que se ven beneficiados los países donde la red se encuentra) que fue financiado con 12 millones de dólares por el Fondo Mundial de lucha contra el Sida, la Tuberculosis y la Malaria.

${ }^{24}$ Página 12: http://www.pagina12.com.ar/diario/dialogos/21-281077-2015-09$\underline{\text { 07.html }}$

M. F.: -A mí me parece también que hay una fuerte campaña publicitaria por parte del sistema prostituyente, en cuanto a querer mostrar que la prostitución es algo bueno que se elige, que no tiene consecuencias negativas, que no hay daños a la salud. (...) Que toda la política que está llevando contra la trata el Gobierno
} 
omnipresente e inaccesible, "el proxenetismo internacional". Señala por ejemplo Marta Fontenla, referente de ATEM y de la Campaña Abolicionista:

\begin{abstract}
A partir de los 90, la presión de los organismos del proxenetismo internacional para obtener la reglamentación de la prostitución se hace cada vez más fuerte y aumenta el dinero que invierten para lograrlo (...) en Argentina estas posiciones están representadas por AMMAR, organizadas en la CTA (...) de esta manera acceden al financiamiento internacional, que a las dirigentes les permite dejar la prostitución. Los sanitaristas y los moralistas han ligado siempre la prostitución con las enfermedades de transmisión sexual (...) ahora el tema es el VIH y se sigue responsabilizando de la transmisión del mismo a las mujeres y travestis, transexuales y transgéneros en situación de prostitución, y las campañas financiadas por los organismos que se ocupan de esta problemática entregan las mayores sumas de dinero a los grupos que se identifican como trabajadores/as del sexo y en los materiales de difusión y trabajo usan solo el término trabajador/a sexual. Como el trabajo de calle con el sector lo deben realizar las personas en situación de prostitución, es otra manera de imponerles el lenguaje ya que de lo contrario no recibirán el exiguo salario que obtienen para trabajar este material... (Fontela, 2012:84,85).
\end{abstract}

ha pegado fuerte. A partir de ahí, ha habido toda una política de parte de estos sectores (prostituyentes). Pero ves que cuando quieren hacer algo público no son más de diez y con la cara tapada. Son siempre las mismas personas, el apoyo es el del financiamiento internacional. Pagan profesionales, pagan publicistas, académicas.

[A propósito de Amnesty:]

M. F.: -Con la crisis económica, la falta de trabajo, el dinero que deja la prostitución... es una forma de conseguir trabajo para las mujeres. Los varones siguen siendo los que tienen el dinero para hacer funcionar el sistema prostituyente y lo ponen ahí. Y el dinero corrompe, compra conciencias, compra profesionales que van haciendo todas políticas de justificación de la prostitución. Yo creo que no hay una sola causa que justifique lo que está pasando. Hay muchas. 
El discurso abolicionista presenta, así, la idea de un lucro económico (a costa del cuerpo de las mujeres) que vendría a corromper las relaciones sociales e imponer una falsa identidad de trabajadoras sexuales:

Nos parece sumamente sospechoso y totalmente cuestionable modificar toda nuestra legislación actual basada en los derechos humanos sólo porque un grupo de mujeres que dice elegir la prostitución de manera voluntaria, quiere que nos convirtamos en un país y en una ciudad reglamentarista. Quienes demandan este cambio son sólo un sector de las personas afectadas, pero con los recursos suficientes (garantizados por un sindicato y por el financiamiento internacional recibido para instalar la figura de "trabajadoras sexuales") para elevar su voz por sobre las demás voces (Carta presentada en la Legislatura de la Ciudad de Buenos Aires, en contra del proyecto de habilitación de locales para la oferta de servicios sexuales de la legisladora María Rachid ${ }^{25}$ ).

Por otro lado, está en relación con todo lo demás la diferencia de financiamientos internacionales que percibe el movimiento reglamentarista en relación al movimiento abolicionista en nuestro país. El primero, nucleado primeramente en AMMAR CTA percibe millones de dólares que fluyen desde la REDTRASEX (Red de Trabajadoras Sexuales de Latinoamérica y el Caribe). Muy diferente es lo que ocurre con las cooperativas que llevan adelante compañeras abolicionistas que estuvieron en situación de prostitución que bien conocemos porque son integrantes como nosotras de frentes más amplios como el FAN (Frente Abolicionista Nacional) o de la Campaña ni Una Mujer Más

\footnotetext{
${ }^{25}$ Dicho proyecto surgió como respuesta frente a la serie indiscriminada de allanamientos legales e ilegales que, con la excusa de la trata, sufrieron durante los últimos años las trabajadoras sexuales de la Ciudad de Buenos Aires. Dichos allanamientos llevaron a la clausura de los lugares donde las trabajadoras ofrecen sus servicios, inclusive cuando se trataba de sus domicilios particulares. Para más detalle, ver Daich y Varela, 2014.
} 
Víctima de las Redes de Trata y Prostitución. Nos consta desde adentro que el financiamiento es escaso o nulo en muchos casos. Es altamente difícil acceder a este financiamiento porque va contra los intereses económicos del poder.

Dentro del manejo de las grandes cantidades de dinero que hay en las organizaciones reglamentaristas, viene incluido el juego de poder de sus dirigentes, quienes deciden qué hacer y qué no con ese dinero, manejándose con las lógicas burocráticas de muchos otros sindicatos. Grandes financiamientos internacionales, relaciones con el proxenetismo local y las redes de trata, sindicalización y lucha por la legalidad... todo sobre ruedas ("Si me tengo que prostituir no es mi revolución!" Fanzine de Grupo Maleza- integrantes del FAN).

Ahora bien, como antropólogas sabemos que intimidad, economía y política no son esferas autónomas y hostiles sino que se imbrican de manera compleja (Zelizer, 2009). Sabemos que el dinero no arrasa siempre con las relaciones sociales, antes bien, crea la posibilidad de nuevas relaciones. Por supuesto que el dinero es también un asunto político pero eso no implica asumir que el financiamiento trae aparejado, siempre y necesariamente, determinadas relaciones ni que impone siempre y de manera unilateral una agenda de trabajo. ${ }^{26}$

El financiamiento nacional $e$ internacional permitió que las organizaciones de trabajadoras sexuales accedieran a una base material necesaria para pensarse y construirse, y para llevar adelante sus proyectos. Claro que éste no ha sido sólo el caso de la Argentina. Kamala Kempadoo (1998) señala cómo las

\footnotetext{
${ }^{26}$ Recuerdo que, muchos años atrás, tuve que evaluar una serie de proyectos financiados por el Estado -a través de un préstamo BID- que versaban sobre un abanico limitado de temáticas de género. Uno de estos proyectos había sido ganado por la organización de trabajadoras sexuales y de las opciones posibles, ellas habían elegido trabajar sobre violencia contra las mujeres. Cuando me tocó conocer el proyecto y sus resultados, fue evidente que estaban trabajando, en verdad, sobre violencia policial. Así, la organización había hecho del proyecto financiado, un ejemplo de plasticidad a la medida de sus intereses.
} 
organizaciones de trabajadoras del sexo poco financiadas, tanto del primer como del tercer mundo, encontraron más fácil obtener dinero cuando la salud pública estaba supuestamente en juego, por lo que las conferencias mundiales sobre VIH dieron a las trabajadoras sexuales una nueva oportunidad tanto para conseguir financiamiento, como para reunirse y revitalizar el movimiento internacional.

No necesariamente el dinero lo cambia todo, son las cosmovisiones existentes las que dan lugar a formas particulares de representarse el dinero (Parry y Bloch, 1989). Para el caso en cuestión, vale entonces preguntarse ¿cuál es esta cosmovisión de las feministas abolicionistas? ¿Por qué hacen este uso negativo del dinero en sus argumentos?

\section{Palabras finales}

No tenemos 12 millones como los que fueron a AMMAR CTA, tenemos una lucha No queremos plata, queremos pleno acceso al ejercicio de nuestros derechos Codo a codo somos muchas más que dos. Sólo la presión social mueve a la voluntad política. Opciones reales ya La prostitución es violencia, no trabajo y nos afecta a todas -Militantes abolicionistas, 8 marzo 2015

No están perdidas, no están perdidas! Son desaparecidas para ser prostituidas!

No son clientes, no son clientes! Son prostituyentes= violadores con billetes

Machista! Cobarde! Tus manos tienen sangre!

Se va a acabar, se va a acabar! Esa costumbre de violar!

Se va a acabar, se va a acabar! Esa costumbre de matar!

Y dale alegría, alegría a mi corazón!! La lucha abolicionista se levantó! Y yaaa veráaas, los mierdas prostituyentes van a caer! Y siiii señooor, vamos a llenar de fiolos el paredón!!

No queremos sindicato, no queremos el carnet! No queremos proxenetas amparados por la ley! (Mujeres por la Abolición de la Prostitución/Abolicionistas Autoconvocadas) 
Las organizaciones de trabajadoras sexuales no sólo buscan una ley de trabajo sexual, también han apoyado distintas iniciativas de quienes se consideran en situación de prostitución y bregan por políticas públicas que les permitan salir de dicha situación. ${ }^{27}$ En los últimos meses no he dejado de preguntarme por qué las organizaciones abolicionistas no pueden tener esta misma actitud, ¿̇por qué no pueden luchar por la inclusión de las mujeres en situación de prostitución y al mismo tiempo respetar el reclamo de quienes se consideran trabajadoras sexuales? No sugiero que deban apoyarlas ni acompañarlas, simplemente respetarlas. Más aun, me pregunto por qué la virulencia de su militancia, ¿Por qué tildan a las dirigentes de las organizaciones como proxenetas? ¿Por qué atacan a las trabajadoras sexuales y sus aliadas acusándolas de haber sido "compradas" por el proxenetismo internacional?

Hasta aquí creo haber mostrado brevemente cómo en la micropolítica abolicionista aparecen el dinero -en su versión de la raíz de todos los males- y el sexo -particularmente en su asociación a estas imágenes sensoriales que provocan asco y rechazo, y en su identificación con la violencia y la violación. Sexo y dinero forman, aquí, parte de un discurso y una política emocional que nos interpela en relación con el tipo de sociedad que queremos.

Podemos pensar los movimientos sociales, como diría Ana de Miguel Álvarez (2003) como "creadores de nuevos marcos de interpretación"; en concreto para el caso que aquí interesa: la importancia de los feminismos que nos han brindado herramientas conceptuales -a las personas de a pie y también a las académicas-

\footnotetext{
${ }^{27}$ Una experiencia de este tipo fue la Mesa de Diálogo Políticas Públicas y Prostitución, llevada adelante por el Programa de Género de la Defensoría General de la Ciudad de Buenos Aires, durante los años 2013 y 2014, donde no sólo aparecieron problemáticas comunes entre trabajadoras sexuales y mujeres en situación de prostitución, sino que, además, AMMAR apoyó las reivindicaciones de las compañeras que no querían ejercer el trabajo sexual. Mi participación en dicha Mesa fue en representación del Instituto Interdisciplinario de Estudios de Género, FILO, UBA.
} 
para pensar las relaciones entre varones y mujeres y para interpretar o re-interpretar la violencia. Claro que no hay un feminismo sino múltiples feminismos que convergen en un movimiento dinámico y muchas veces contradictorio. Entre estos feminismos, hay un feminismo abolicionista cuya interpretación respecto del mercado del sexo como violencia de género ha permeado buena parte de las discusiones en la arena pública.

Este sector del feminismo abolicionista no sólo ha reinterpretado aspectos de la sociedad, específicamente en lo que hace al mercado del sexo, sino que además propone nuevas emociones en relación con ello: el sexo comercial siempre es violencia, es violación paga, es sufrimiento, es esclavitud sexual ¿Cómo no empatizar y solidarizarse con tamaño mal? Hace apenas unos meses, una integrante de la Campaña Abolicionista decía en una entrevista con un diario local:

¿Siempre tuvieron postura abolicionista?

N. P.: -Hay cuestiones intuitivas en principio. Hay una palabra que hoy está en desuso, la compasión. Una ve que son mujeres que están pasando una situación extrema, de necesidad o exposición. Es un feminismo salvaje, sin tener una reflexión profunda (...) Algo intuitivo, salvaje hay, por lo que te rebelás contra la injusticia y contra la violencia. Después eso lo vas procesando intelectualmente, te vas formando, te vas asociando con otras mujeres y tenés algo mucho más profundo, más reflexivo. ${ }^{28}$

En la misma línea, el grupo Maleza sostenía en su fanzine:

Apelamos a la empatía de las académicas de clase media que están viviendo sus vidas en su casa propia, charlando con amigas o familia con un vinito que no es de veinte pesos. Y con empatía nos referimos a poder pensar desde una qué nos pasaría si la prostitución fuera nuestro trabajo diario, si el miedo y el asco fueran nuestras emociones diarias. 
Si lo emocional antes que puramente experiencia subjetiva habla de fenómenos sociales que dan cuenta de situaciones, relaciones y posiciones morales (Lutz, 1986), cabe pensar este abolicionismo como una verdadera política de las emociones. Ello así, puesto que expone a los sujetos a determinadas narrativas que construyen, finalmente, un saber emocional capaz de guiar el deber ser sentimental. Así, el dolor y el sufrimiento de la narrativa de la prostitución se transforman en la compasión y la empatía de las militantes abolicionistas. Las feministas abolicionistas están genuinamente preocupadas por este sufrimiento y esta injusticia, sentimientos que las une como grupo y que asegura que las prostitutas permanezcan como el objeto de dicha emoción. La preocupación de unas, ciertamente no es la de todas. La compasión une a algunas, las otras son principalmente el objeto de conmiseración.

Así, las emociones mantienen a este movimiento, valga la redundancia, en movimiento. La explicitación de las emociones no sólo habla sobre las relaciones entre sujetos y eventos (Daich, Pita y Sirimarco, 2007) sino que hace de amalgama; los sentimientos aglutinan al grupo.

¿Pero qué pasa cuando quienes son objeto de los sentimientos que nos unen como movimiento político disputan nuestras producciones narrativas y nuestras interpretaciones de la realidad social? Cuando, en el año 2002, un grupo de prostitutas adoptó para sí la identidad de trabajadoras sexuales, la alianza con las feministas se quebró. Desde entonces, fueron construidas como un obstáculo para el ideario abolicionista. $\mathrm{O}$, para decirlo de otro modo, desde entonces las trabajadoras sexuales se tornaron las verdaderas aguafiestas de este feminismo abolicionista.

Muchas veces he oído a las trabajadoras sexuales organizadas decir que las feministas (refiriéndose a las abolicionistas) no son sus enemigas, que el enemigo es principalmente la policía. Sin embargo, en tanto y en cuanto disputen los significados propuestos por el movimiento abolicionista, difícilmente no sean vistas por éste como, en palabras de Ahmed (2004), "el origen de los malos sentimientos" o 
como el obstáculo para un mundo más igualitario. Quizás las trabajadoras sexuales organizadas estén experimentando aquello que alguna vez nos advirtió Gilles Deleuze (1987), el hecho de que si estás atrapado dentro del sueño de otro, estás en problemas.

\section{Referencias bibliográficas}

AHMED, Sara. Collective Feelings or the impressions left by others. Theory, culture \& society, vol. 21 (2), 2004, pp.25-42. 18.

. The politics of good feeling. ACRAWSA vol. 4, n 1, 2008, pp.1-

. Feminism and the History of Happiness. Signs, vol. 35, n ${ }^{\circ} 3$, 2010, pp.571-594.

CUTULI, Soledad. Entre el escándalo y el trabajo digno. Etnografía de la trama social del activismo travesti en Buenos Aires. Tesis de Doctorado en Antropología, FILO, UBA. 2015.

DAICH, Deborah. ¿Abolicionismo o reglamentarismo? Aportes de la antropología feminista para el debate local sobre la prostitución. Runa "Archivos para la Ciencia del Hombre", XXXIII (1), 2012, pp.71-84.

; VARELA, Cecilia. Entre el combate a la trata y la criminalización del trabajo sexual: las formas de gobierno de la prostitución. Delito y Sociedad, no 38,2014, pp.63-86.

; PITA, María Victoria; SIRIMARCO, Mariana. Configuración de territorios de violencia y control policial: corporalidades, emociones y relaciones sociales. Cuadernos de Antropología Social, vol. 25, 2007, pp.71-89.

DeLEUZE, Gilles. Qu'est-ce que l'acte de création? Conférence donnée dans le cadre des mardis de la fondation. Femis, 1987 [http://www.cip-idf.org/article.php3?id_article=2045].

EsCoBAR, Arturo. Bienvenidos a Cyberia. Notas para una antropología de la cibercultura. Revista de Estudios Sociales no 22, 2005, pp.1535.

FERRERO, Juan P.; GURRERO, María S. El sindicalismo de movimiento social. Algunas reflexiones en torno del concepto. En: FERnÁNDEZ, 
Arturo (ed.). Estados y sindicatos en perspectiva latinoamericana. Buenos Aires, Prometeo, 2007, pp.105-130.

FONTENLA, Marta. Una aproximación a los hechos y debates en torno a la prostitución y la trata de mujeres y niñas/os. Brujas, año 31, n ${ }^{\circ} 38$, 2012, pp.81-90.

GuIMARÃES, Mário J. L. Jr. O Ciberespaço como cenário para as ciências sociais. ILHA, vol. 2, n 1,2000 , pp.139-155.

GuY, Donna. El sexo peligroso. La prostitución legal en Buenos Aires 1875-1955. Buenos Aires, Sudamericana, 1994.

JUSTO VON LURzer, Carolina. Putas, el estigma. Aproximación a la organización de las mujeres que ejercen la prostitución en la Ciudad de Buenos Aires. Question, vol. 1, $\mathrm{n}^{\circ}$ 12, 2006 [http://perio.unlp.edu.ar/ojs/index.php/question/article/view/295].

KEMPADOO, Kamala. Globalizing sex workers'rights. Canadian women studies 22, 1998, pp.143-150.

LEAVITT, John. Meaning and feeling in the Anthropology of emotions. American Ethnologist, vol. 23, n³, 1996, pp.514-539.

LUTZ, Catherine. The domain of emotion words on Ifaluk. American Ethnologist, vol. 9, n 1,1982 , pp.113-128.

. Emotion, thought and estrangement: emotion as cultural category. Cultural Anthropology, vol. 1, n 3, 1986, pp.287-309.

Catherine y WHITE, Geoffrey. The anthropology of emotions. Annual Review of Anthropology, vol. 15, 1986, pp.405-436.

MESTRE I Mestre, Ruth. Trabajo sexual e igualdad. En: HOLGADO FERnÁndeZ, Isabel. (ed.) Prostituciones. Diálogos sobre sexo pago. Barcelona, Icaria, 2008, pp.55-72.

Miguel Álvarez, Ana. El movimiento feminista y la construcción de marcos de interpretación. El caso de la violencia contra las mujeres. Revista Internacional de Sociología n 35, 2003, pp.127-150.

MORCILlO, Santiago. Entre el burdel, la cárcel y el hospital. Construcción socio-médica de la prostituta. Espacio Abierto vol. 24, n 2, 2015, pp.299-316. 
PARRY, Jonathan y BLOCH, Maurice. Introduction: Money and the morality of exchange. En: PARRY, Jonathan y Maurice BLOCH (eds). Money and the morality of exchange. New York, Cambridge University Press, 1989, pp.1-32.

PISCITELl, Adriana. Viagens e sexo on-line: a internet na geografia do turismo sexual. Cadernos Pagu (25), Campinas-SP, Núcleo de Estudos de Gênero-Pagu/Unicamp, 2005, pp.281-326.

. Violências e afetos: intercâmbios sexuais e econômicos na (recente) produção antropológica realizada no Brasil. Cadernos Pagu (42), Campinas-SP, Núcleo de Estudos de Gênero-Pagu/Unicamp, 2014, pp.159-199.

RuBIO, Ana. La teoría abolicionista de la prostitución desde una perspectiva feminista. En: HOLGADO FERNÁNDEZ, Isabel. (ed.) Prostituciones. Diálogos sobre sexo pago. Barcelona, Icaria, 2008, pp.73-95.

SABSAY, Leticia. Fronteras Sexuales. Espacio urbano, cuerpos y ciudadanía. Buenos Aires, Paidós. 2011.

VARElA, Cecilia. Del tráfico de las mujeres al tráfico de las políticas. Apuntes para una historia del movimiento anti-trata en la Argentina (1988-2008). Publicar, año X, n XII, 2012, pp.35-64.

. La campaña antitrata en la Argentina y la agenda supranacional. En: DAICH, Deborah y Mariana SIRIMARCO (coords.). Género y violencia en el mercado del sexo. Política, policía y prostitución. Buenos Aires, Biblos, 2015, pp.109-149.

Tiscornia, Sofía; SarRabayrouse, María José; Eilbaum, Lucía. De los edictos de policía al Código de Convivencia Urbana. Las trágicas paradojas de los procesos de construcción de espacios de convivencia. En: TISCORNIA, Sofía (comp.). Burocracias y violencia. Estudios de antropología jurídica. Buenos Aires, Antropofagia, 2004, pp.89-125.

ZELIZER, Viviana. La negociación de la intimidad. Buenos Aires, FCE, 2009. 